\title{
Some energy problems of the Irkutsk region and ways of solving them
}

\author{
Vladimir Golovshchikov*, Melentiev Energy Systems Institute of Siberian Branch of the \\ Russian Academy of Sciences, Irkutsk, Russia
}

\begin{abstract}
The article deals with the more significant energy problems of Irkutsk region, the solution of which play an important role for the sustainable and constant functioning of energy complex from production to energy consumption
\end{abstract}

\section{Introduction}

The problems of regional energy sector cannot be considered in isolation from the ongoing power industry reform in the Russian Federation (RF).

In 2018, it has been 17 and 15 years since the RF Government Resolution No. 526 On Power Industry Reforming and Federal Law (FL) No. 35 On Power Industry that set direction to reforming and developing Russia's Interconnected Power System (IPS) came into effect, respectively.

We can claim the following:

1) The main goals of the reform [1] have not been attained:

- Uncontrollable growth in electricity and heat rates has not been stopped;

- $\quad$ Expected mass investments in the power industry have not been made;

- Power industry has not become a highly effective industry;

- Balance of interests between heat and electricity suppliers and consumers has been upset;

- Wholesale Electricity and Capacity Market (WECM) and Retail Electricity and Capacity Market (RECM) were established but their organization and operation cannot satisfy, first of all, the consumer, etc. (see, Goals and Objectives in Resolution No. 526).

2) Despite the correct initial preconditions on the necessity to reform the electric power industry, many methods and means, and even some basic principles of the reforms, were chosen incorrectly.

3) Relying on the reforming ways of some foreign countries, reformers allowed neither for the specific features and experience of these countries, nor for the features of Russia and the previous, mostly successful, long-term experience of operation and development of the USSR power industry.

4) Power industry turns from an infrastructural branch into a sectoral one, and, which is even worse, in many cases, into an appendage of major entities, when large power plants operate only for the needs of these entities (for example: electric power industry and the aluminum industry in Irkutsk Region).

*Corresponding author: vladgo@isem.irk.ru 
5) Hydro power plants (HPPs), nuclear power plants (NPPs), and large condensing power plants (CPPs) have obtained essential advantages in the wholesale electricity and capacity market compared to combined heat-and-power plants (CHPs).

6) In the energy sales, the last-resort suppliers have a monopoly (for example, in Irkutsk region they control over $80 \%$ of the electricity and heat market).

In many aspects (in terms of realizing the situation), we have returned to where we were fifteen years ago, and we have to begin much anew: to agree on basic conceptual provisions, to develop or essentially revise legal and regulatory framework for the power industry.

7) The main goals and objectives of Federal Law No. 261-fz (2009) On Energy Conservation have not been accomplished:

- $\quad$ there is no reliable information on the energy conservation potential;

- $\quad$ metering devices have not been provided for all consumers; for example, in Irkutsk Region, in 2017, the situation with metering was as follows: cold water supply $-35 \%$, hot water supply $-35 \%$, heat supply $-37,8 \%$, and power supply $-71 \%$.

- there has been no zealous switching to renewable energy sources (RESs); moreover, there is an increase in production of conventional energy resources.

8) The 2010 energy-efficiency programs have become obsolete, and if revised, only formally.

Over the last three-four years, there have been a great number of various events (round tables, workshops, conferences, forums, including international ones, etc.), and many events are held now. They differ in the level, the composition of participants and organizers and in the extent to which they touch upon the problems of electric power industry. Participants in these "meetings" discuss certain problems of individual "components" of the electric power industry (the issues of reliability, power losses, smart grids, digitization, etc.) and the problems of conceptual nature.

Unfortunately, all these events often end with either an invitation to appeal to the Government, State Duma, and other federal institutions, and/or to get together again to discuss problems but there have been virtually no practical results.

\section{Some considerations on the energy situation in the Irkutsk Region [2]}

In 2016, the specific fuel consumption for electricity and heat production in the Irkutsk Region tended to increase and exceeded the Russian average. For example, the average specific fuel consumption for electricity production at thermal power plants in the Irkutsk Region was 331.8 gce $/ \mathrm{kWh}$ versus $303.8 \mathrm{gce} / \mathrm{kWh}$ in the Russian Federation. The fuel-andenergy resource utilization efficiency in the end consumption was also essentially lower than the Russian average parameter: 68.8 (the Irkutsk Region) versus 75.7 (the Russian Federation).

The parameters of energy- (electricity- and heat-) GRP ratio in the Irkutsk Region and the Russian Federation also differ essentially: the 2016 Energy-GRP ratio in the Irkutsk Region was $35.3 \mathrm{kgce} /$ thousand Rub. versus $19 \mathrm{kgce} /$ thousand Rub. in the Russian Federation. The presented data demonstrate high energy intensity of the key industries in the Irkutsk region.

The above data show that there is an essential potential in the Irkutsk Region to boost energy efficiency and conservation.

Over the last two years, there has been another negative trend for such a major power company as Irkutskenergo: transition from long-term electricity export to import to the Irkutsk region. In 2010, the Region exported 8-10 bn kWh, whereas, in 2016, 5 bn $\mathrm{kWh}$ 
was imported from the Interconnected Electric Power System of Siberia. Herewith, the installed capacity utilization factor of electric power plants in the Irkutsk Region was 41.2 for electricity, and 17.6 for heat (on average, as of 2016). There are several reasons why this is so:

- a low-water period over the last years,

- it is unprofitable to burn coal at CHPs under the existing situation in the WECM and RECM,

- legislation requires CHPs to sell electricity at the WECM and heat at the RECM, which makes CHPs unprofitable.

Besides the above problems, there are some others to highlight:

1. Adoption of the alternative boiler-house mechanism that has been gradually introduced in the Russian Federation may lead to a growth in heat rates for all consumers.

2. Wear and tear of fixed assets in the energy sector (first of all, small power sources and distribution networks of $35 \mathrm{kV}$ and below, where the depreciation reaches $80 \%$ ).

3. Failure to implement the Order of the Government of the Russian Federation No. 511-r of 03.04.2013 dealing with "consolidation of electric grid assets of Territorial Grid Organizations (TGOs)". In the Irkutsk Region, there are above 20 TGOs of different capacity and efficiency (only few of them are successful; some are on the verge of bankruptcy). The service zones of these TGOs interface, and often overlap. The heterogeneity and the great number of TGOs decrease the reliability of power supply and increase the tariff for power transmission through the grids (first of all, due to operation costs). This tariff has already exceeded $60 \%$ (on average) in the final electricity rate for the consumer.

4. The existing "boiler" method (boiler at the top) of funding grid companies leads to an unfair form of payment for the grid services for the consumer. The idea of the method is as follows: a utility company (a financial and economic entity) collects the money for electricity from the consumers, and then transfers part of the amount (for transmission services) to the largest grid company ('boiler' operator) that distributes this part among other TGOs (as a rule, smaller ones) connected to the grids of this large company. The tariffs for power transmission for various TGOs are established by a State regulatory body (for example, Tariff Service in the Irkutsk Region).

5. Some earlier adopted important resolutions have not been implemented (or have been implemented partly):

5.1. In late 2010, the author of this paper proposed launching the development and implementation of a Smart Grid pilot project, as an advanced global trend. For 2012, $21 \mathrm{~m}$ Rub was allocated to create an operating fragment (comprising 6 substations) with its trial run planned for the third quarter of 2012. However, because the Governor of the Irkutsk Region retired in the 2012 first half, as well as the Director General of the regional energy enterprise "Oblcommunenergo", the work on this project stopped almost instantly.

5.2. In 2013, a combined wind-solar power plant was put into a trial run on the Lake Baikal coast that was valued at above $30 \mathrm{~m}$ RUB [3]. Design and implementation of the project faced great problems. The unresolved problems in the plant operation have resulted factually in its inadequate operation for the time being.

5.3. In 2013, the pilot project on creation of two "Smart homes" was implemented in Angarsk. This project (about $120 \mathrm{~m}$ Rub budget funds) involved advanced solutions in computer-aided control of electricity and heat consumption on the basis of renewable energy sources. As a result of "organizational problems", by 2015 this project had not gained any effect. Moreover, after the next change in the executive authority of the Irkutsk Region similar projects were not recommended for further implementation.

5.4. The issue of constructing a power plant using the casing-head gas in Ust-Kut town has been periodically raised. Simultaneously, about $600 \mathrm{MW}$ are "locked" in the area of 
Ust-Ilimsk town, and it is more feasible to use the latter by constructing an additional circuit of the $500 \mathrm{kV}$ transmission line.

5.5. Since 2010, the problem of heat supply of Baikalsk town has not been settled, although the scientific and technical community offered effective solutions.

5.6. The issue of a second large heat source for Irkutsk remains open. A heavy emergency at the Novo-Irkutsk CHP can lead to catastrophic consequences for the city.

5.7. There is no final resolution on the conversion of the Irkutsk Region to gas even for a medium term (despite the available largest Kovykta gas-condensate field).

5.8. There is no reasonable option for the social and economic development of the Irkutsk Region, and, as a result, there is no comprehensive program for the energy development there.

The problems listed in Point 5 are caused not only by shortage of funds, but, first of all, by a mix of the distorted market approaches, manifestations of monopolism, command and administrative management methods, a laissez-faire attitude sometimes shown in the socialpolitical environment. It is this mix that hampers the regional energy development, and, as a result, it is an additional hindrance for the whole regional economy and social sphere. One should note that the situation in the Irkutsk Region is peculiar: five Governors (who naturally formed their own management teams) have changed over less than a decade. Thus, each new team either postponed many previous correct solutions until better time, or revised them.

One should admit that there are examples of implementing effective projects in the Irkutsk Region, such as: solar power plants in Tofalaria, application of heat pumps at the Ust-Ilim HPP, upgrading of small heat sources, etc. However, in general, the state of the regional energy sector leaves much to be desired.

\section{Methods for solving the problems}

At the federal level, it is necessary:

1. To revise some legislation provisions in order to:

- $\quad$ allow CHPs to operate in both WECM and RECM. The calculations performed at Melentiev Energy Systems Institute SB RAS (based on the 2015 data) showed that for the major consumers of the Irkutsk Region the electricity cost may decrease by 30\%;

- develop and approve a technique to determine the rates for power transmission that will consider distances from consumers to supply centers (now they are not considered: the rate is the same for all consumers);

- $\quad$ allow the Federation entities to decide on expediency of combining the activities on energy supply and sale.

2. Regulatory bodies of all levels should fully enforce the passed legislative acts (in terms of upgrading of equipment, metering, reliability and efficiency indices, preparation for winter, etc.).

At the regional level, it is necessary to:

1. Correct and approve the program of the social and economic development of the Irkutsk Region as a basis of the regional energy sector development program both for the medium and long terms. The above program should involve two scenarios: a pessimistic scenario and a scenario considering possible positive trends in the economy and energy sector.

2. Develop a detailed program of distribution (35 kV and lower) network development as the technological bases for RECM and for creating Smart Grids with distributed generating sources. (Resolution No. 823 of the Russian Government as of 2009, this Resolution concerns only electrical networks of $110 \mathrm{kV}$ and higher). 
3. Ensure unconditional implementation of the earlier passed resolutions on regional energy sector irregardless of any changes in the executive authorities in the Region, with fixation of the personal responsibility.

4. Revise the regional program for the energy efficiency and energy saving enhancement and arrange careful revision of similar municipal programs.

5. Intensify the implementation of Resolution No. 511-r of the Russian Government in terms of consolidation of network assets based on the most effective grid companies, which would gain an economic effect of no less than $300 \mathrm{~m}$ Rub per year according to preliminary estimates (Resolution No. 184 of the Russian Government as of 2015 on TGO Criteria is actually not implemented) [4].

6. Approve (at the federal level) a special lowered electricity rate for electric boiler plants at Lake Baikal, which will eliminate the problems of heat supply to settlements and environmental pressure.

7. Create the regional center of competence and management of the energy development in the Irkutsk Region (the relevant Ministry does not perform these functions).

\section{References}

1. V.O. Golovshchikov. Problems of power industry restructuring in Russia and their effect on market relations. Energy Market, No. 5 (2016)

2. V.O. Golovshchikov. Regional energy sector: operation, problems, and development prospects. Energy Expert, No. 6 (2016)

3. V.O. Golovshchikov. Creation of a combined wind-solar power plant at Lake Baikal first steps in using renewable energy sources in East Siberia. Automation and IT in Power Engineering, No. 8 (2013)

4. V.O. Golovshchikov. Problems of territorial distribution grid companies. Electric Power - Transmission and Distribution, No. 3 (2014) 